
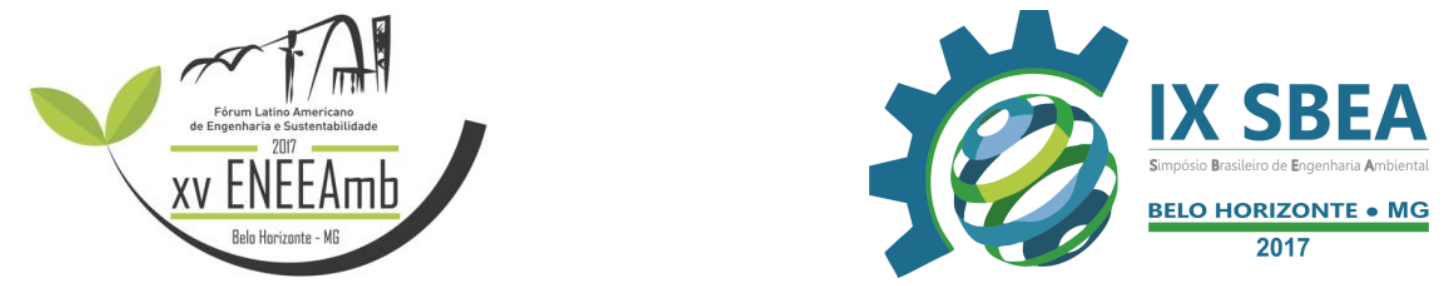

EDUCAÇÃO AMBIENTAL

\title{
ANÁLISE DA PERCEPÇÃO AMBIENTAL NA ESCOLA MUNICIPAL RUY DA SILVEIRA BRITTO
}

Erika Joana Nabiça Borges - e-mail: erikanabica10@gmail.com Universidade de Estado do Pará

Adriano Vitor Monteiro Dias - e-mail: adrianoodias13@gmail.com Universidade de Estado do Pará

Ermeson Freitas da Silva - e-mail: ermesonfreitasdasilva@gmail.com Universidade de Estado do Pará

Tadeu Mello Rodrigues - e-mail: tadeumello98@gmail.com Universidade de Estado do Pará

Dr. Manoel Alves da Silva - email: manoelalves42@gmail.com Universidade de Estado do Pará 

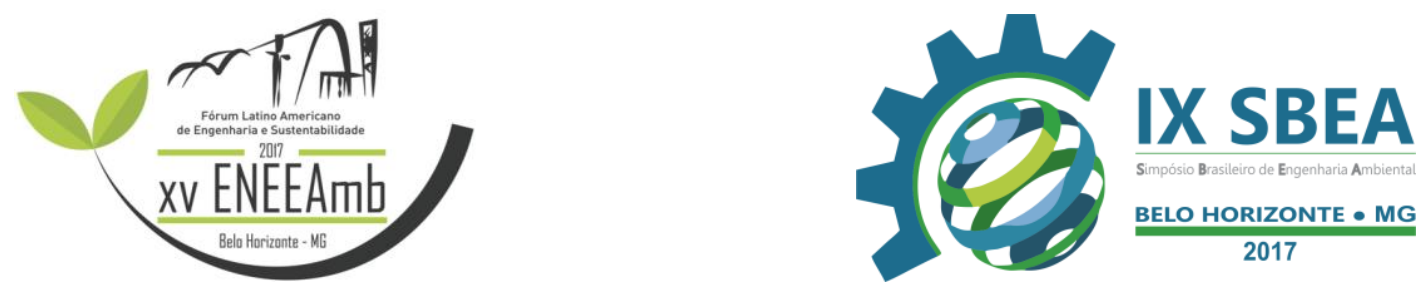

\section{RESUMO}

A problemática do lixo vem aumentando nas cidades brasileiras, por conta da gestão e gerenciamento de resíduos sólidos não efetivos. A educação é uma poderosa ferramenta de colaboração nesta gestão. O presente trabalho objetivou avaliar os conhecimentos ambientais dos estudantes do $1^{\circ}$ ao $5^{\circ}$ ano. A temática é sobre a colaboração da Educação Ambiental (EA) no gerenciamento dos resíduos da Escola Municipal Ruy da Silveira Britto, localizada no bairro do Marco, em Belém. A metodologia do trabalho foi realizada a partir da aplicação de um formulário a 161 alunos, com perguntas elaboradas a partir dos fatores de EA e indicadores de sustentabilidade. Dos resultados, podemos concluir que, 64\% dos participantes têm conhecimento sobre meio ambiente e $74 \%$ sobre reciclagem, porém não sabem definir o que é resíduo ou rejeito, e o que seria meio ambiente; sobre o destino dos resíduos, 31\% sabia para onde vão os resíduos gerados em sua instituição; $85 \%$ tinha interesse de pôr em prática a coleta seletiva, e $76 \%$ de melhorar seu ambiente escolar. Logo, pode-se concluir que há importância de trabalhar a EA desde o ensino de base, pois a partir desta, que foi possível notar mudanças de valores, comportamentos, sentimentos e atitudes dos participantes.

Palavras-chave: Educação ambiental, escola, gerenciamento de resíduos.

\section{INTRODUÇÃO/OBJETIVO}

A educação é um importante meio transformador e, portanto um instrumento de modificar e gerir o meio ambiente a favor de interesse coletivo ou individual. É também uma ação humana transformadora da natureza em cultura, atribuindo sentidos e trazendo ao estudante a experiência de participar da vida e a compreensão de estar no mundo (CARVALHO, 2012).

A Política Nacional de Educação Ambiental dispõe no art. 10 da Lei 9.795 que a educação ambiental será desenvolvida como uma prática educativa integrada, contínua e permanente em todos os níveis e modalidades do ensino formal, ou seja, ela não deve ser tratada como uma disciplina específica no âmbito escolar básico, mas articulada às atividades dos estudantes, além da participação social no engajamento da conservação e recuperação do 

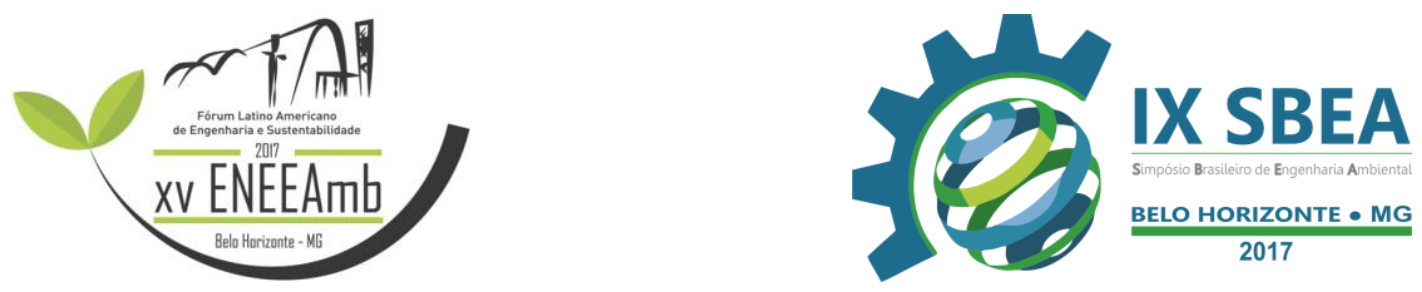

meio ambiente; e o Poder Público também deve promover políticas públicas para a incorporação da educação ambiental.

O ser humano é totalmente dependente do meio ambiente, este engloba exatamente tudo o que nos cerca. Com a crescente degradação ambiental é necessário ter essa percepção, pois é direito do cidadão ter um ambiente equilibrado para se ter qualidade de vida. Desta forma, a educação ambiental no ensino de base entra com o objetivo de desenvolver a consciência dos problemas ambientais ocasionado pelo uso excessivo dos recursos (PRONEA, 2014, p. 11-12 e 23-25).

Todos os problemas ambientais mais relevantes à sociedade estão associados ao lixo, devido a sua continuidade de produção em todas as classes sociais (RODRIGUES, 1998). É importante ressaltar que os comportamentos atuais são reflexos de períodos históricos como o desenvolvimento rápido do capitalismo, pós-guerra, que tiveram como grande influência o modelo de consumo norte americano "american way of life" ( LEITE, 2005).

Diante disso, os indicadores de sustentabilidade são de fundamental importância na analogia entre a gestão de resíduos sólidos in loco e as atividades rotineiras de certa população (MALHEIROS et al, 2012). Esses indicadores devem mostrar dados que possibilitem a análise das transformações físicas e sociais; além de fomentar a formulação de políticas públicas (Scherer et al, 2008).

Tendo como base os indicadores desenvolvidos por Leão et al (2008), a presente pesquisa, cujo o caráter é exploratório, tem como objetivo avaliar a compreensão dos estudantes sobre os princípios de sustentabilidade na escola municipal Ruy da Silveira Britto, Belém-Pa.

\section{METODOLOGIA}

A técnica de pesquisa utilizada foi a entrevista estruturada, a qual consiste em um encontro entre duas pessoas a fim de auferir informações a respeito de determinado assunto por meio de perguntas pré determinadas. Utilizou-se como ferramenta o formulário que segundo Nogueira (1968, p.129 apud Lakatos \& Marconi, 2007, p.212) se define como 

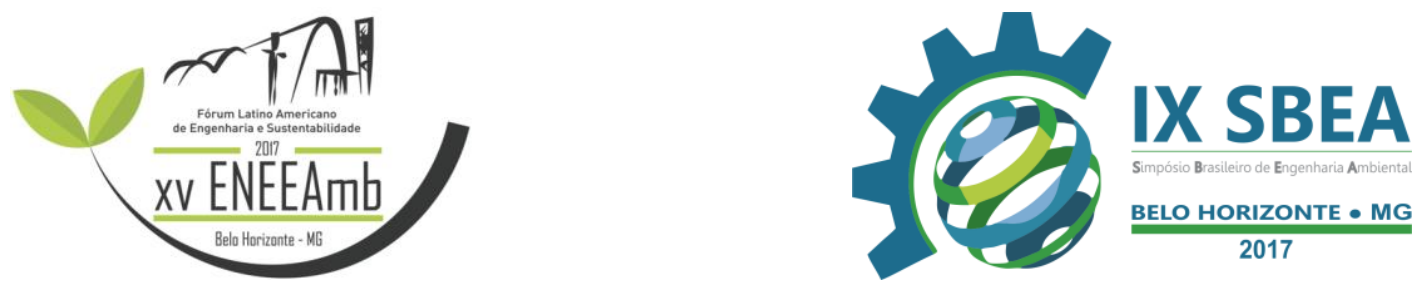

conjunto de perguntas destinadas à coleta de dados resultantes da observação e do interrogatório, cujo preenchimento é feito pelo entrevistador, à medida que recebe informações do entrevistado sob sua orientação.

A pesquisa consistiu na aplicação de um formulário eletrônico com smartphones aos estudantes do ensino fundamental I ( $1^{\circ}$ ao $5^{\circ}$ ano). Cada ano é subdividido em duas turmas. $\mathrm{O}$ formulário foi estruturado com perguntas diretas sobre resíduos, coleta seletiva, compostagem e reutilização, baseadas nos seguintes indicadores de sustentabilidade segundo Leão, 2008:

$\checkmark$ Reduzir a geração de lixo;

$\checkmark$ Coletar e tratar adequadamente o lixo;

$\checkmark$ Garantir ambiente limpo e saudável, sem acúmulo de lixo;

$\checkmark$ Acondicionar o lixo de preferênciap

$\checkmark \quad$ Dar destino apropriado ao lixo sem poluir o meio ambiente; separando-o para coleta seletiva;

\section{Caracterização da área}

A instituição escolhida para a pesquisa foi a Escola Municipal Ruy Da Silveira Britto, localizada na Travessa Dr. Enéas Pinheiro, 2871 - Marco, Belém - PA.

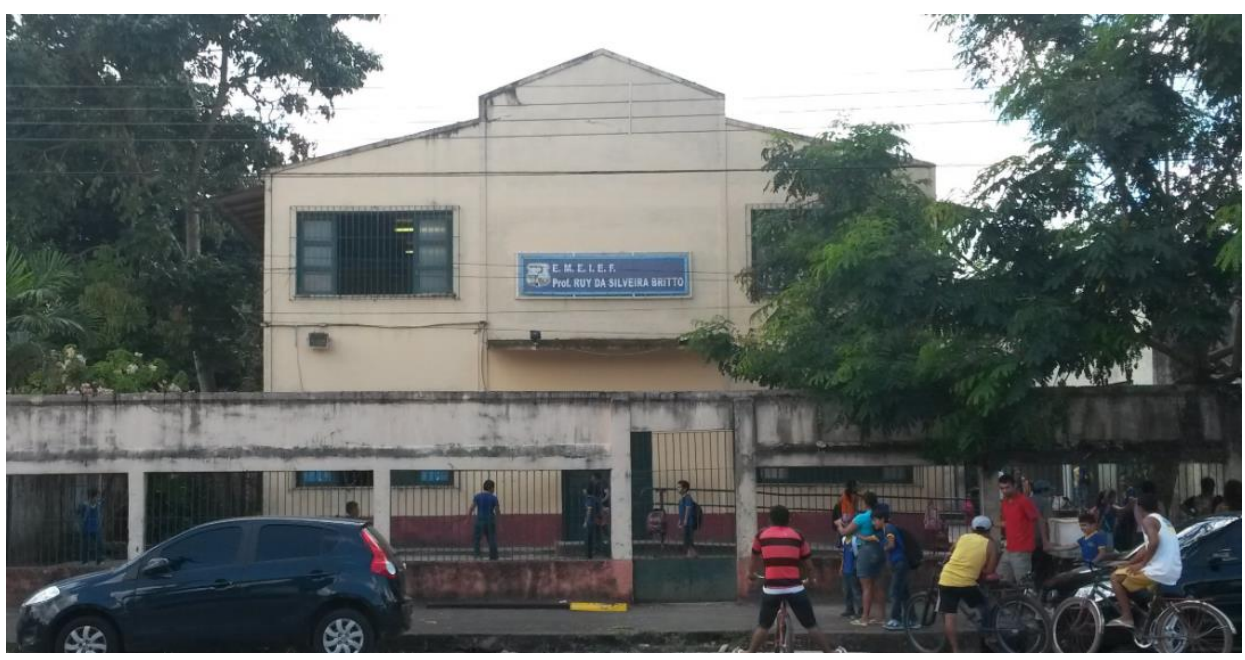

Figura 1- Fachada da E.M.E.I.E.F. Prof.Ruy da Silveira Britto.

\section{População e Amostra}



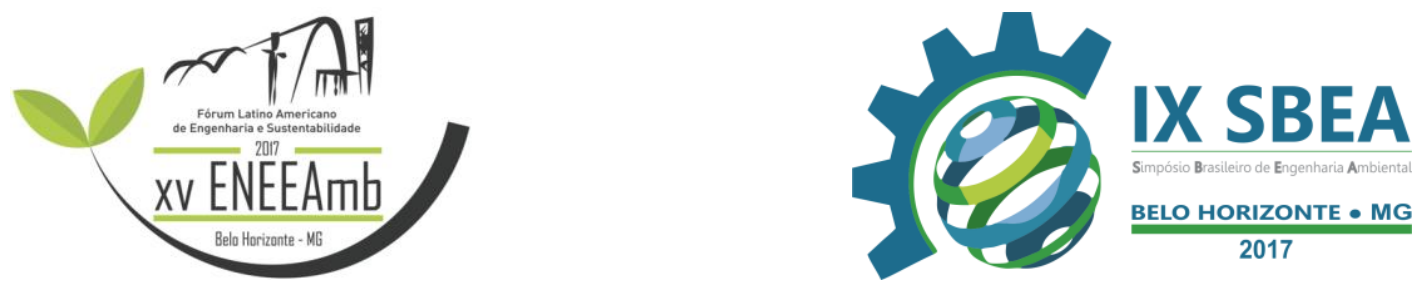

Geralmente em um estudo, não é viável avaliar todos os indivíduos de uma determinada população. Diante disso, a inferência estatística proporciona elementos para generalizar as análises obtidas da amostra para a população (Correa, 2003). O tipo de amostragem utilizada foi a probabilística aleatória, permitindo que cada estudante tivesse a mesma probabilidade de $\begin{array}{llllll}\text { ser } & \text { escolhido. } & \text { Calculou } & \text { se } & \text { através }\end{array}$ (http://www.publicacoesdeturismo.com.br/calculoamostral/) a amostra do total de estudantes do Fundamental I com 95\% de confiança e 5\% de significância, e realizou-se a proporção para cada turma em relação ao total como ilustrado na Tabela 1.

Tabela 1 - Total de alunos e amostra.

\begin{tabular}{|l|l|l|l|l|l|l|}
\hline Fundamental I & $1^{\mathbf{o}}$ ano & $2^{\mathrm{o}}$ ano & $3^{\mathrm{o}}$ ano & $4^{\mathrm{o}}$ ano & $5^{\mathrm{o}}$ ano & Total \\
\hline $\mathrm{N}^{\mathrm{o}}$ de alunos & 20 e 21 & 26 e 30 & 27 e 31 & 29 e 29 & 30 e 31 & 274 \\
\hline $\mathrm{N}^{\mathrm{o}}$ de formulários & 12 e 12 & 15 e 18 & 16 e 18 & 17 e 17 & 18 e 18 & 161 \\
\hline
\end{tabular}

\section{As entrevistas}

Todo o processo teve acompanhamento da coordenação da escola e dos respectivos professores de cada turma. Utilizamos o Formulário Online do Google Inc. ${ }^{\circledR}$ para as entrevistas onde foram feitas 16 perguntas para uma amostra de 161 participantes, sendo todos alunos do Ensino Fundamental $\mathrm{I}\left(1^{\circ}\right.$ ao $5^{\circ}$ ano). Além disso, para que todos os estudantes tivessem a mesma probabilidade de serem entrevistados, usamos o aplicativo Número Aleatório (UX Apps ${ }^{\mathrm{TM}}$ ) para o sorteio.

\section{RESULTADOS E DISCUSSÃO}

\section{Gênero dos entrevistados}

Dos entrevistados $54,3 \%$ era do sexo feminino, e $45,7 \%$ do sexo masculino tendo, portanto certo equilíbrio entre a amostra representativa de cada gênero.

\section{Integração com o meio ambiente}



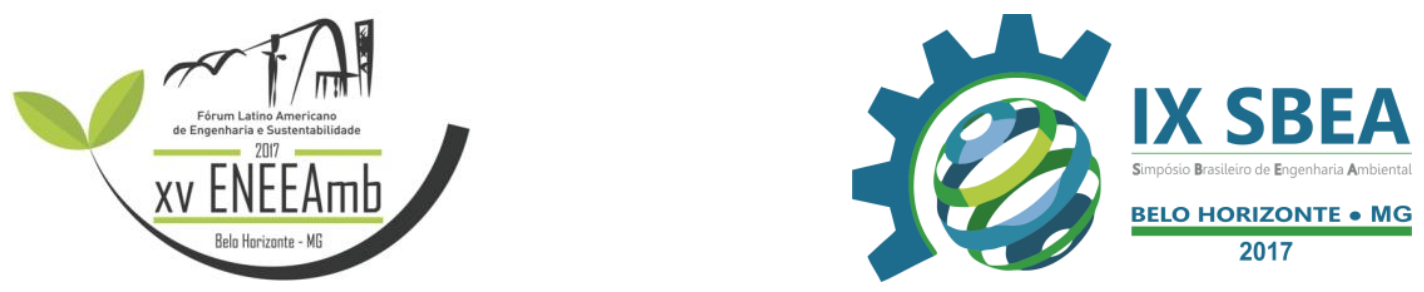

Quando os entrevistados foram questionados sobre a integração com o meio ambiente, 64\% responderam que "Sim", e 7\% responderam "Não". Quando foram indagados porque da resposta, responderam que meio ambiente significa a natureza, por isso não faziam parte, então foi possível notar que eles fazem a separação de meio ambiente e ser humano, não considerando que existe relação entre eles. Isto pode ser observado no Gráfico 1:

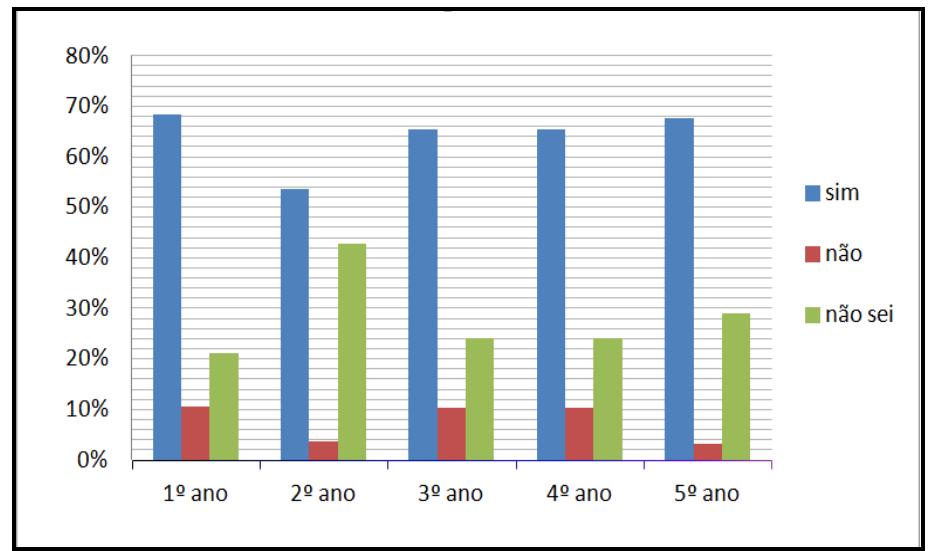

Gráfico 1: Integração com o meio ambiente.

\section{Reduzir a geração de lixo}

A PNRS, Lei no 12.3051/2010 define lixo ou rejeito como "resíduos sólidos que, depois de esgotadas todas as possibilidades de tratamento e recuperação por processos tecnológicos disponíveis e economicamente viáveis". Logo é importante saber diferenciar material reciclável ou reutilizável do lixo, e poder associá-lo aos principais problemas ambientais, pois essa percepção reduz a geração do lixo.

Nos Gráfico 2 , é ilustrada a opinião dos estudantes sobre o que pode ser considerado lixo. Verificou-se que $84,67 \%$ dos estudantes responderam que embalagens após usadas deveriam ir para o lixo e $75,94 \%$ responderam que papel também deveria ser descartado. Dentre os materiais, "roupas" apresentou o menor percentual com 17,46\%. Notou-se que os estudantes apresentam pouco conhecimento quanto a reutilização desses materiais. Alguns classificaram espontaneamente papel, móveis e embalagens como materiais recicláveis e/ou reutilizáveis. O Gráfico 3, representa o conhecimento deles acerca de qual tipo de resíduo é 

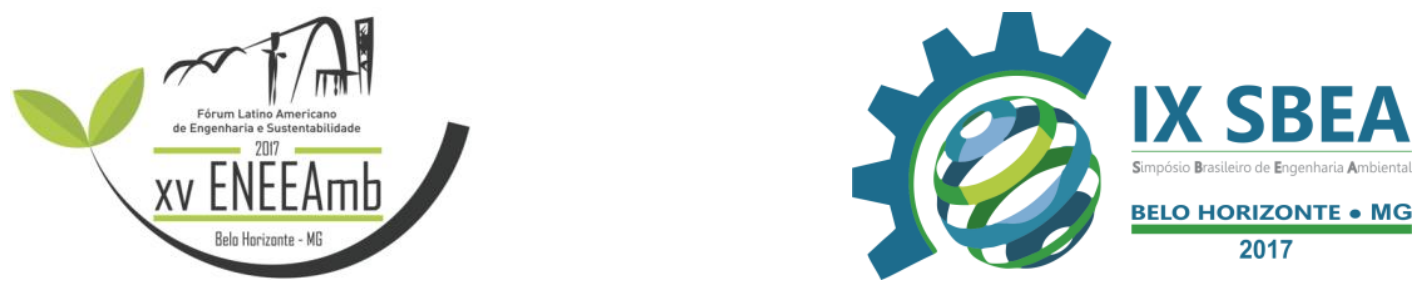

mais produzido na escola. Constatou-se que 45,68\% dos estudantes responderam que "papel" é o mais produzido, em segundo o "plástico" com 34\%.

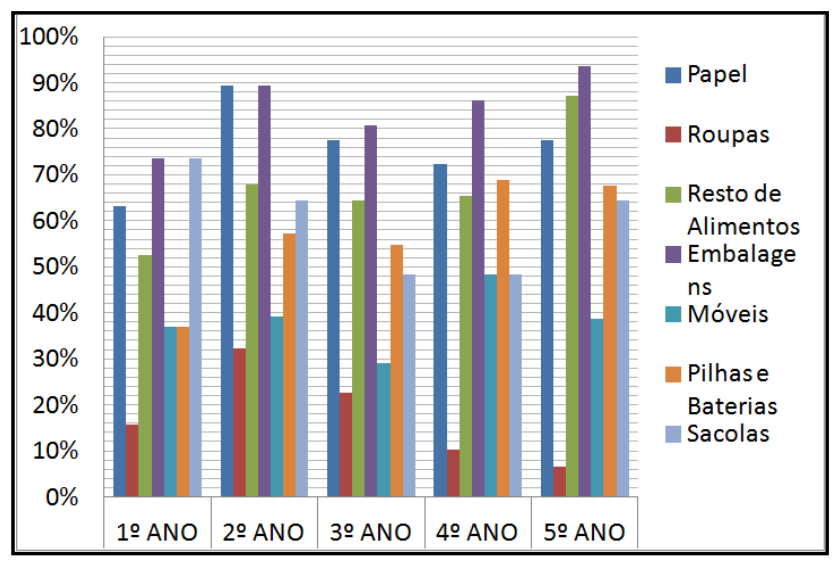

Gráfico 2: Concepção do que pode ser lixo.

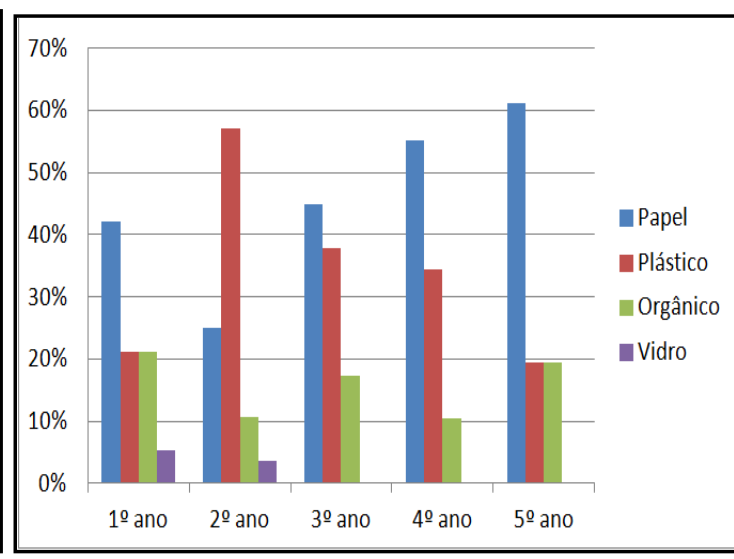

Gráfico 3: Produção de resíduo escolar.

\section{Garantir ambiente limpo e saudável, sem acúmulo de lixo}

Quando os estudantes foram indagados acerca da limpeza do ambiente escolar, percebeu-se que quanto mais avançada a série/ano do estudante, mais exigente era sua percepção de limpeza, de acordo com o Gráfico 5. Em contradição eles não demonstraram costume na contribuição na melhoria do ambiente escolar, de acordo com o Gráfico 4.

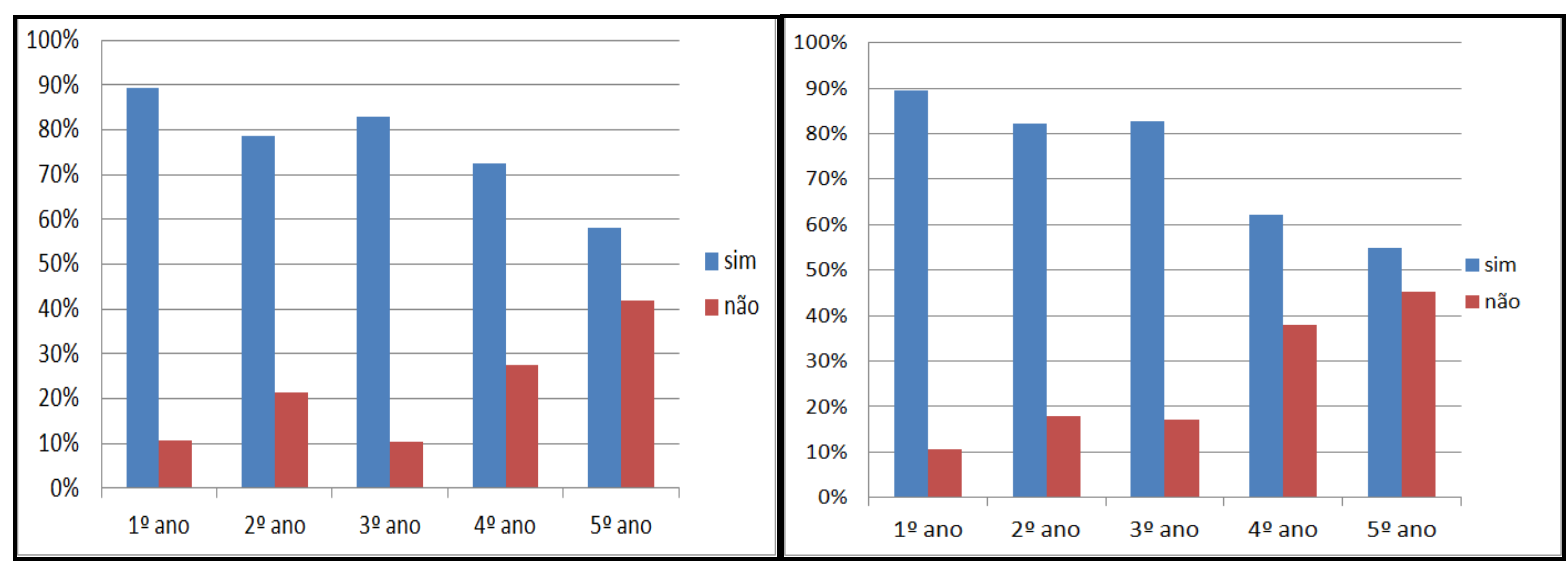

Gráfico 4: Melhoria da escola.

Gráfico 5: Limpeza da escola. 

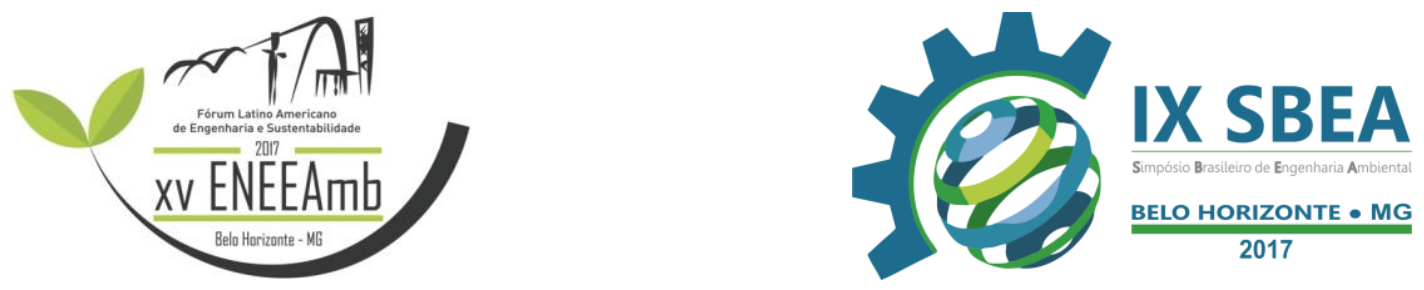

\section{Acondicionar o lixo de preferência separando-o para coleta seletiva}

Apesar de nem todos conhecerem sobre coleta seletiva e sua importância, e também de não ter aplicação efetiva na escola, a maioria achava que deveria ocorrer a separação do lixo, conforme observado no gráfico 6, pois de acordo com eles, esse material poderia ser reciclado ou reutilizado. Pode-se notar também que conforme avançava a série, os estudantes conseguiam identificar a se há ou não a coleta seletiva no local onde eles convivem, conforme o gráfico 7 .

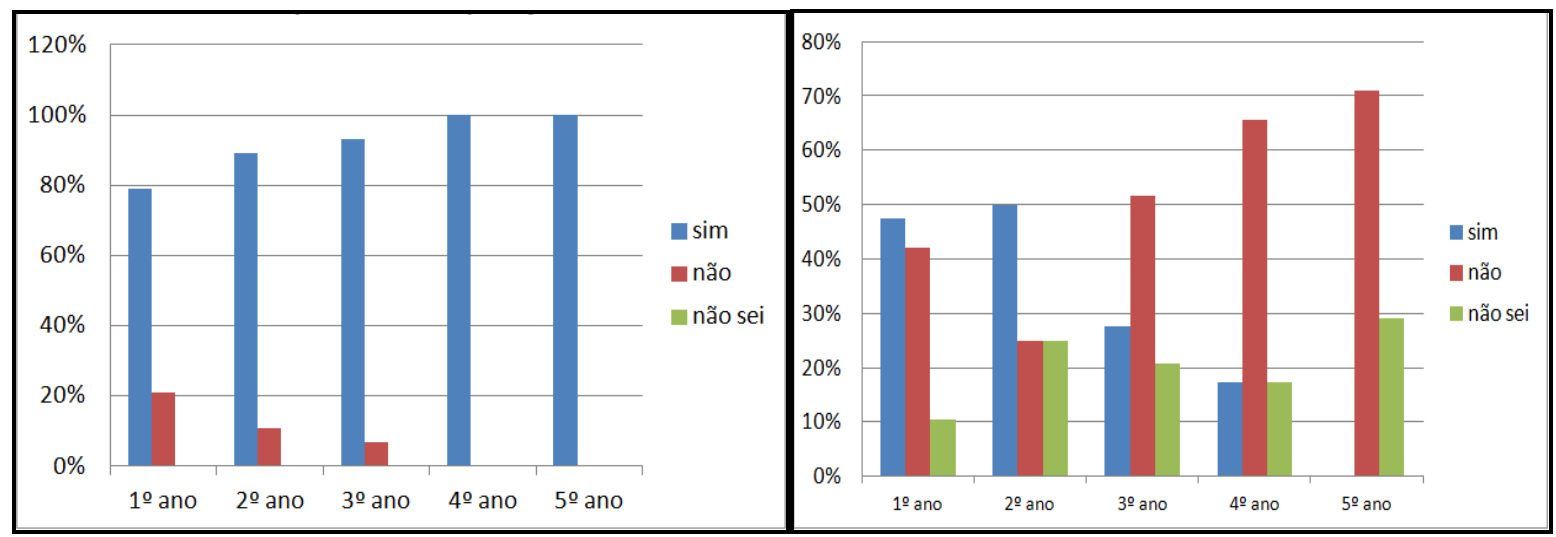

Gráfico 6: Importância da separação de lixo.

Gráfico 7: Separação de lixo.

\section{Coletar e tratar adequadamente o lixo}

Separação do lixo, também chamada coleta seletiva, segundo a Lei no 12.3051/2010, “é a coleta de resíduos sólidos previamente segregados conforme sua constituição ou composição". Esta técnica tem várias vantagens, como, aliviar os lixões e aterros sanitários, chegando até eles apenas os rejeitos; através da separação grande parte dos resíduos sólidos gerados em casa pode ser reaproveitada; os materiais que podem ser reciclados economizam recursos naturais e podem gerar renda para catadores de lixo, que dependem dos resíduos descartados para sobreviver. Conforme o Gráfico 9, 74,53\% dos entrevistados já tinham conhecimento sobre reciclagem, e 55,64\% tinham conhecimento acerca da compostagem. Importante notar que mais de $50 \%$ dos estudantes do $1^{\circ}$ ano demonstraram conhecimentos acerca dos três tipos de tratamento do "lixo". 

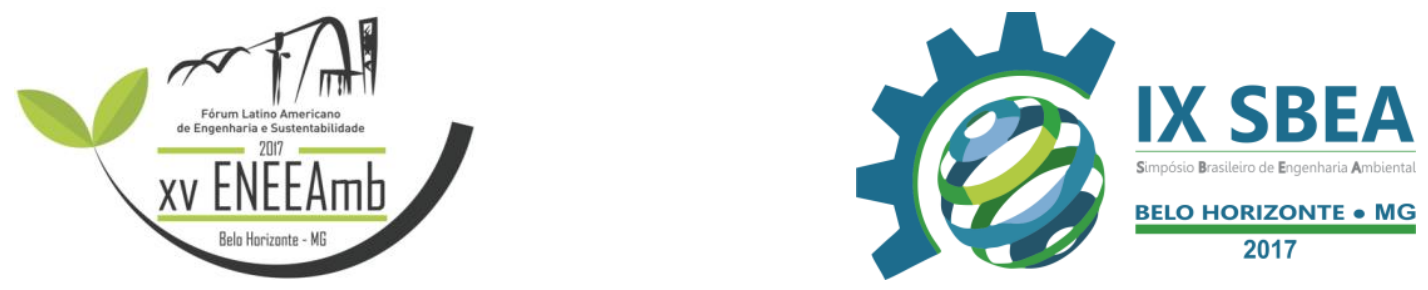

Sobre o interesse na separação do resíduo, 85,53\% dos entrevistados demonstraram interesse, conforme ilustrado no Gráfico 8. Porém, percebeu-se que eles não sabem o porquê dessa importância.

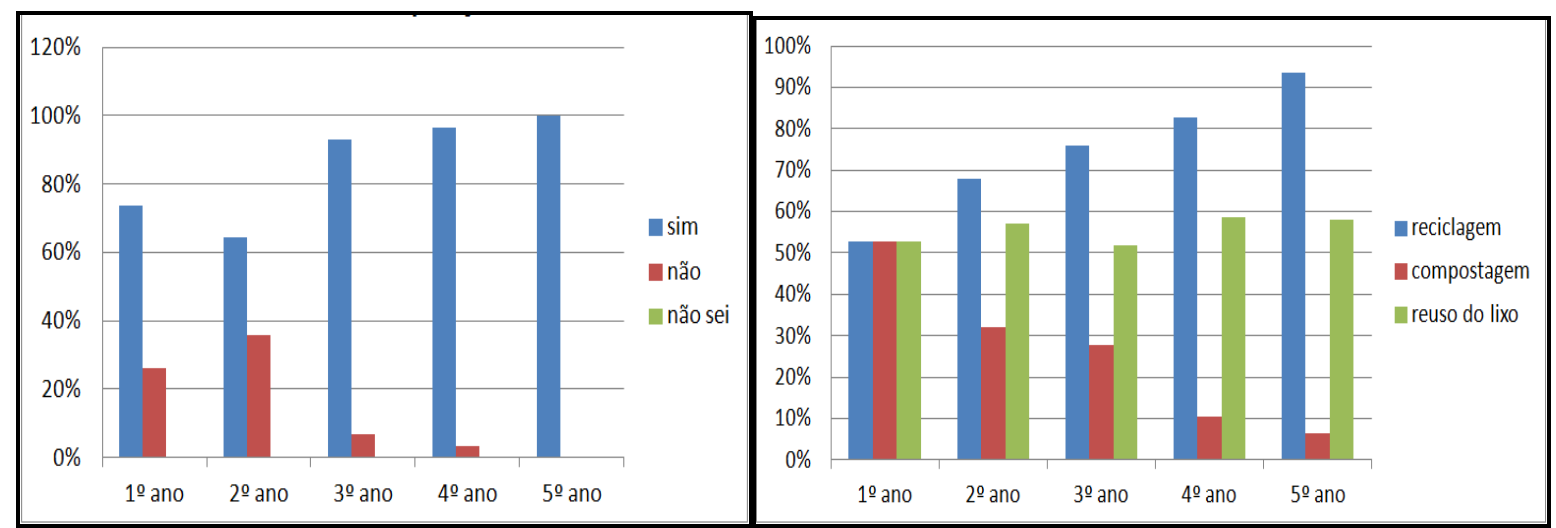

Gráfico 8: Separação do lixo.

Gráfico 9: Reciclagem, compostagem e reuso do lixo.

\section{Dar destino apropriado ao lixo sem poluir o meio ambiente}

Como ilustrado no Gráfico 10 pode-se notar que há uma branda diferença do conhecimento da destinação do lixo em relação idade do estudante. Apesar de muitos conhecerem o sistema de coleta, 69,22\% ainda desconhecem o destino final dos resíduos produzidos na escola. Alguns estudantes relataram que o destino final dos resíduos era as margens dos Canais a Céu aberto.

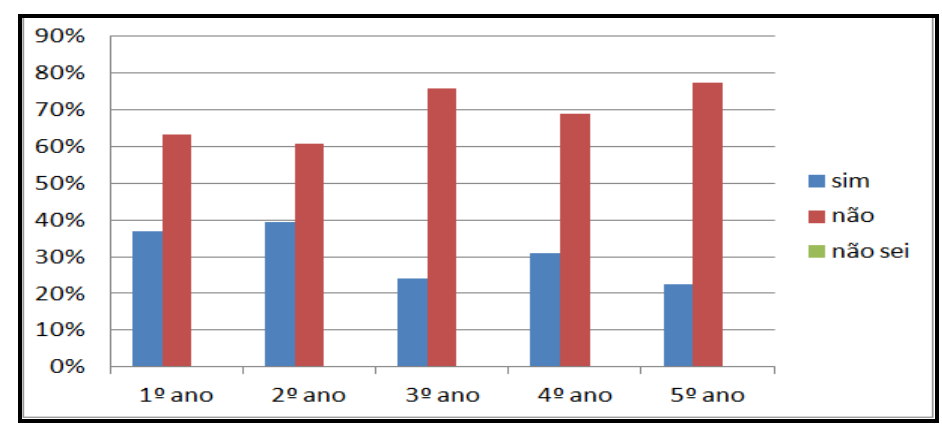

Gráfico 10: Destino do lixo. 

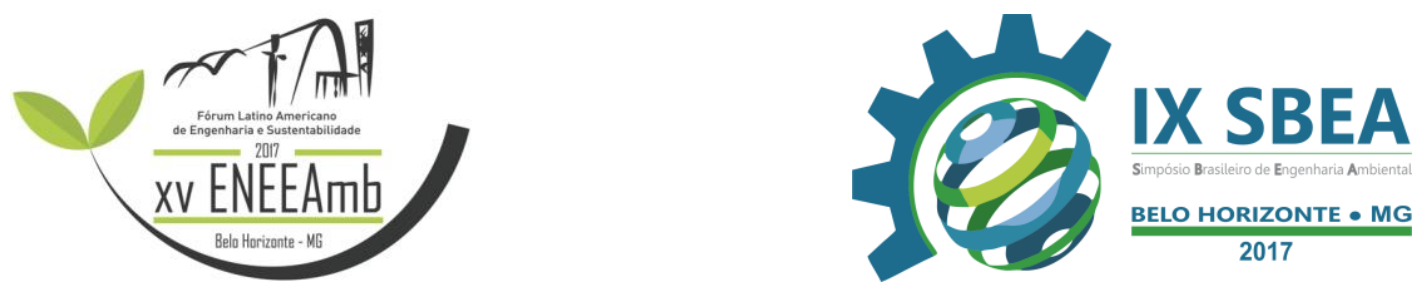

\section{CONCLUSÕES/RECOMENDAÇÕES}

A prática da educação ambiental tem importância fundamental na formação de indivíduos conscientes e na mudança de valores e atitudes. Notou-se que os estudantes já possuem conhecimentos sobre os princípios de sustentabilidade adquiridos em casa e/ou no ambiente escolar, porém muitos desconhecem conceitos importantes. As crianças do $3^{\circ}, 4^{\circ} \mathrm{e}$ $5^{\circ}$ ano mostraram uma melhor percepção sobre questões ambientais, pois tinham melhor compreensão do que estava sendo perguntado.

A instituição em questão não adota a educação ambiental de forma contínua e nem a coleta seletiva, realiza atividades periódicas acerca do meio ambiente. Vale ressaltar que para ser implantada a EA, a causa deve ser agregada pela gestão superior com atividades contínuas.

Deixa-se como recomendação analisar a percepção ambiental com os estudantes do Ensino Fundamental II, tanto como fator comparativo entre as mudanças nas respostas dos formulários, como também ter um apanhado sobre quais anos apresentam um melhor conhecimento sobre fatores ambientais mesmo sem ter matérias específicas sobre educação ambiental.

\section{REFERÊNCIAS BIBLIOGRÁFICAS}

BRASIL. Ministério do Meio Ambiente. Política nacional de resíduos sólidos. 2. ed. Brasília: Câmara dos Deputados, Edições Câmara, 2012. 73 p. - (Série legislação ; n. 81). Disponível em: < http://fld.com.br/catadores/pdf/politica_residuos_solidos.pdf $>$. Acesso em: 10 de abr. 2017. 10-11 p.

BRASIL. Ministério do Meio Ambiente. Programa Nacional de Educação Ambiental. 4. ed. Brasília, 2014. Disponível em: <http://www.mma.gov.br/publicacoes/educacaoambiental/category/98-pronea>. Acesso em: 10 abr. 2017. 11-12 e 23-25 p.

BRASIL. Ministério do Meio Ambiente. Política Nacional de Educação Ambiental: Lei No 9.795/1999.

Disponível

em: 

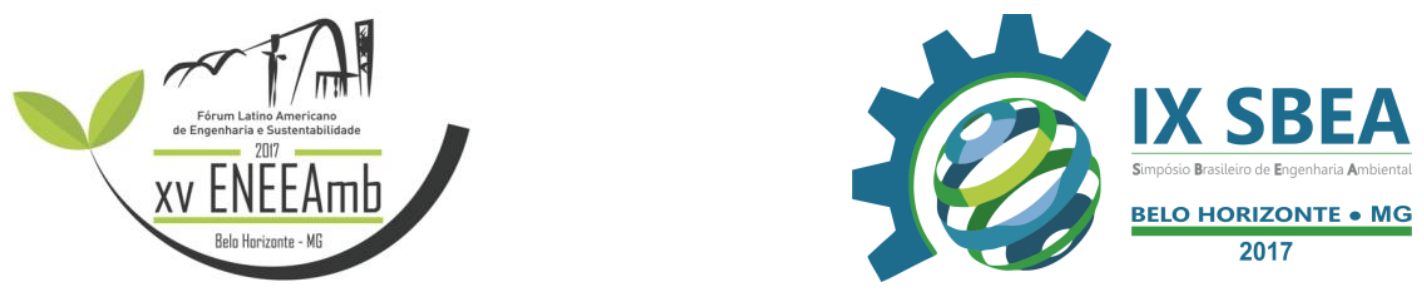

$<$ http://portal.mec.gov.br/secad/arquivos/pdf/educacaoambiental/lei9795.pdf $>$. Acesso em: 28 de abr. 2017.

CARVALHO, I. C. M. Educação ambiental: a formação do sujeito ecológico. 6. ed. São Paulo: Cortez, 2012. 11-20 p.

CORREA, Sonia Maria Barros Barbosa. Probabilidade e Estatística. Belo Horizonte: PUC Minas $2003 . \quad$ Virtual, Disponível $<$ http://www.inf.ufsc.br/ vera.carmo/LIVROS/LIVROS/livro_probabilidade_estatistica_2a_e d.pdf>. Acesso em: 20 mai. 2017.

GOMES, L.G.F.F. Novela e sociedade no Brasil. Niterói: EdUFF, 1998. 137 p.

LEÃO, N.; ALENCAR, C.; VERÍSSIMO, A. Belém Sustentável 2007. 1. ed. Belém: IMAZON, 2008.

LEITE, Tânia Maria Campos. Entraves Espaciais: brownfields caracterizados por aterros de resíduos sólidos urbanos desativados no município de São Paulo. 2005.

MALHEIROS, T.D. COUTINHO, S.M.V. JR, A.P. Construção de indicadores de sustentabilidade. USP-Universidade de São Paulo, 2012.

MARCONI, A. Marina; LAKATOS, M. Eva. Fundamentos de metodologia científica. 6. ed. São Paulo: Atlas, 2007.

RODRIGUES, Arlete Moysés. Produção e consumo do e no espaço: problemática Ambiental Urbana. São Paulo: Hucitec, 1998.

SCHERER, C.M.S.; BRANDÃO, H.T.G. Indicadores de Sustentabilidade Ambiental: Um Estudo Para o Município de Marabá - PA. UEPA-Universidade do Estado do Pará, Marabá, 2008. 